ВІСНИК

ОДЕСЬКОГО НАЦІОНАЛЬНОГО

МОРСЬКОГО УНІВЕРСИТЕТУ

№ 3 (63), 2020
HERALD

OF THE ODESSA NATIONAL

MARITIME UNIVERSITY

№ 3 (63), 2020

УДК 65.012.34:338.47

DOI 10.47049/2226-1893-2020-3-118-142

\title{
ОПТИМИЗАЦИЯ ЛОГИСТИЧЕСКИХ ОПЕРАЦИЙ ПРИ ПОСТРОЕНИИ МАРШРУТОВ ДОСТАВКИ
}

\author{
Н.Н. Поддубная \\ ст. преподаватель кафедры «Управление логистическими системами и проектами»
}

\section{А.О. Василенко, И.А. Ковтун}

студенты 4 курса факультета Транспортных технологий

Одесский наџиональный морской университет, Украина, Одесса

УДК 65.012.34:338.47

DOI 10.47049/2226-1893-2020-3-118-207

Аннотация. Современный этап развития экономики характеризуется жесткой конкуренцией среди компаний транспортной отрасли. Сложившаяся ситуация побуждает компании учитывать интересы потребителей, снижая цены на предоставляемые услуги без потери ее качества, а это возможно при переходе от конкуренции к сотрудничеству и как следствие объедению и развитию экономического, технического и технологического потенциалов. Надо отметить, что при таком объединении, именно логистический подход является действенным инструментом, позволяющим получить синергетический эффект. Важной задачей интеграчии имеющихся потенциалов, является учет всех операиий, выполняемых в процессе создания продукта с иелью снижения их стоимости и предотвращения дублирования.

В статье проведен анализ общепринятых определений логистической и грузовой операиий, уточнено понятие логистическая операция. Обоснована необходимость учета всех логистических и коммерческих операций при формировании сквозного тарифа. На приведенном примере доставки автомобилей из США в Украину, приведён алгоритм принятия решения при построении логистической системы. На основе сетевого графика предложены экономико-математические модели, оптимизируюшие маршрут доставки.

Ключевые слова. Логистическая система, логистические операцุии, оптимизаџчия логистических операщий.

(С) Поддубная Н.Н., Василенко А.О, Ковтун И.А., 2020 
ВІСНИК

ОДЕСЬКОГО НАЦІОНАЛЬНОГО

МОРСЬКОГО УНІВЕРСИТЕТУ

№ 3 (63), 2020
HERALD

OF THE ODESSA NATIONAL

MARITIME UNIVERSITY

№ 3 (63), 2020

УДК 65.012.34:338.47

DOI 10.47049/2226-1893-2020-3-118-142

\title{
ОПТИМІЗАЦІЯ ЛОГІСТИЧНИХ ОПЕРАЦІЙ \\ ПРИ ПОБУДОВІ МАРШРУТІВ ДОСТАВКИ
}

Н.М. Піддубна

ст. викладач кафедри «Управління логістичними системами і проектами»

О.О. Василенко, І.О. Ковтун

студенти 4 курсу факультету Транспортних технологій

Одеський національний морський університет, Украӥна, Одеса

Анотація. Сучасний етап розвитку економіки характеризується жорсткою конкуренцією серед компаній транспортної галузі. Ситуація, щчо склалася спонукає компанії враховувати інтереси споживачів, знижуючи ичіни на послуги, щуо надаються без втрати ї̈ якості, а ие мож-ливо при переході від конкуренції до співпраці і як наслідок смакота $i$ розвитку економічного, технічного та технологічного потенціалів. Треба відзначити, щуо при такому об'єднанні, саме логістичний підхід є дієвим інструментом, щзо дозволяє отримати синергетичний ефект. Важливим завданням інтеграції наявних потенціалів, $\epsilon$ облік всіх операцій, які виконуються в процесі створення продукту з метою зниження їх вартості та запобігання дублюванню.

У статті проведено аналіз загальноприйнятих визначень логістичної і вантажний операцій, уточнено поняття логістична операція. Обтрунтовано необхідність врахування всіх логістичних $і$ комерційних операцій при формуванні наскрізного тарифу. На наведеному прикладі доставки автомобілів з США в Украӥну, наведено алгоритм прийняття рішення при побудові логістичної системи. На основі мережевого графіка запропоновані економіко-математичні моделі, оптимізують марирут доставки.

Ключові слова. Логістична система, логістичні операції, оптимізація логістичних операцій

UDC 65.012.34:338.47

DOI 10.47049/2226-1893-2020-3-118-142

OPTIMIZATION OF LOGISTICS OPERATIONS WHEN BUILDING DELIVERY ROUTES

\author{
N. Poddubnaya \\ Senior Lecturer of the Department of Management of Logistic Systems and Projects \\ O. Vasilenko, I. Kovtun \\ 4th year student of the Faculty of Transport Technologies \\ Odessa National Maritime University, Ukraine, Odessa
}


Abstract. The current stage of economic development is characterized by fierce competition among transport companies. The current situation encourages companies to take into account the interests of consumers, lowering prices for services provided without losing its quality, and this is possible in the transition from competition to cooperation and, as a result, unification and development of economic, technical and technological potential. It should be noted that with such a combination, it is the logistics approach that is an effective tool for obtaining a synergistic effect. An important task of integrating the existing capabilities is to take into account all operations performed in the process of creating a product in order to reduce their cost and prevent duplication.

The article analyzes the generally accepted definitions of logistics and cargo operations and clarifies the concept of a logistics operation. The necessity of taking into accounts all logistics and commercial operations when forming a through rate is substantiated. On the given example of the delivery of cars from the USA to Ukraine, an algorithm for making a decision is given when building a logistics network. On the basis of the network diagram, economic and mathematical models are proposed for optimizing the delivery route.

Keywords. Logistics network, logistics operations, optimization of logistics operations.

Постановка проблемы. Глобализация и интеграция мировой экономики привела в жесточайшей конкуренции среди компаний, оказывающих услуги по доведению сырья, материалов и готовой продукции до потребителя.

До недавнего времени процесс доставки разбивался на локальные подсистемы видов транспорта или компаний, которые последовательно передавали груз, перемещая его к потребителю. При этом вопрос минимизации общих затрат не рассматривался, поскольку каждая компания решала обособленные задачи максимизации прибыли за предоставленные услуги. В сложившихся ныне условиях конкурентной борьбы среди транспортных компаний, пришло понимание необходимости перехода от конкуренции к сотрудничеству. Это означает, что для поиска и удержания потребителя услуг, необходимо интегрировать деятельность компаний, различных видов транспорта по доведению груза до потребителя. При таком подходе интегрированные компании имеют общую цель, задачи и, возможно, материальную базу. Такие временно интегрированные компании и транспорт образуют логистическую систему, основной задачей которых являться доведение товара до потребителя с соблюдением основных принципов логистики, а именно: Right product (требуемый продукт), Right quality (требуемого качества), Right quantity (в требуемом количестве), Right time (в установленное время), Right place (в нужное 
место), Right customer (конкретному потребителю), Right costs (с оптимальными затратами).

При логистическом подходе возможно не только выполнение перечисленных принципов, но и, за счет объединения совместных усилий, расширение и улучшение спектра предоставляемых услуг.

Транспортно-логистическая услуга является уникальной для потребителя, зависит от вида груза, на которую она направлена и имеет свою ценность. На практике, затраты на транспортно-логистические услуги в неявном виде включают в «сквозную» ставку, которую, зачастую, принимают, основываясь на уже сложившейся практике работы в рассматриваемом направлении для аналогичного груза. Такой подход не исключает возможность выбора не оптимальной операции в транспортнологистической услуге. Как результат, сформированный маршрут может быть оптимальный не для конкретной ситуации и груза, а предоставленная услуга не будет оптимальной и, соответственно, уникальной.

Итак, исходя из основных принципов логистики, связанных с возможной минимизацией затрат и времени на доставку, важной задачей является полное (формализованное) описание всех возможных логистических операций, определяющих логистическую услугу, с указанием времени и затрат на их выполнение. Поэтому большой практический интерес вызывают методы и модели, с помощью которых возможно детально отобразить альтернативные логистические операции, выполняемые в процессе доставки, и в результате чего выбрать оптимальный маршрут.

Анализ исследований и публикаций. Решение задач выбора оптимальных схем доставки нашли свое отражение в учебных пособиях Аникина В.А. [1], Гаджинского А.М. [2], Миротина Л.Б. [3], Сергеева В.И. [3], Воевудского Е.Н. [5], Гольштейна Е.Г., Юдина Д.Б. [6], Постана М.Я. [7] и др. Надо отметить, что в перечисленных источниках основной акцент делается на рассмотрение структуры экономикоматематических моделей и не уточняются составляющие затратных характеристик, оптимизируется только транспортная составляющая, чаще всего, на локальных участках.

В работе [8] оптимизируются интегрированные производственные и транспортные затраты. В трудах [9-12] рассмотрены постановки задач логистической направленности и экономико-математические модели, учитывающие возможность выбора поставщиков, наличие в системе доставки распределительных центров и оптимизацию выбора не только маршрута, но и способа доставки. В [13] приводится методика рассмотрения маршрута доставки, исходя из операций, выполняемых при перемещении груза. В работе [14] рассмотрена концептуальная модель сквозной тарифной ставки, где выделены «признаки составляющих» сквозного тарифа и предпринята попытка их минимизации. 
Несмотря на достигнутые результаты, с нашей точки зрения, по-прежнему остается актуальной разработка новых методических подходов, методов и моделей, позволяющих решать задачу выбора оптимального маршрута доставки груза путем выбора альтернативных логистических операций на пути следования груза, а также «прозрачного» расчета сквозного тарифа.

Цель исследования состоит в уточнении понятия «логистические операции», разработки алгоритма их учета при построении схем доставки, а также разработки новых и адаптации уже имеющихся моделей поддержки принятия решений для оптимизации выбора логистических операций на пути перемещения материального потока от поставщика до конечного потребителя.

Основные результаты исследования. В настоящее время практическая логистика получила широкое распространение в экономических отношениях. Существует множество определений логистики как науки и практики, изучение которых позволяет сделать следующее обобщение. Логистика - это наука и практика, направленные на согласованное управление действиями отдельных предприятий (производственных, транспортных, складских, торговых и др.) по доведению материального потока (готовой продукции, полуфабрикатов, сырья) до конечного потребителя с выполнением, так называемых, «семи правил логистики», которые и обеспечивают конечную цель логистического управления.

Принцип системности логистики обусловил поэтапную, с течением времени, интеграцию ранее разрозненных систем поставки, производства и сбыта, что привело к появлению понятия логистическая система (ЛС). В литературных источниках $[2 ; 3 ; 4]$ приводятся формулировки этого понятия, которые не конкретизируют отличительные признаки ЛС от любой экономической системы. Так, например, в [2] под ЛС понимают адаптивную систему с обратной связью, выполняющую те или иные логистические функции и, как правило, состоящую из нескольких подсистем имеющих развитые связи с внешней средой. С нашей точки зрения, упомянутое определение описывает свойства, а не признаки, по которым можно идентифицировать логистическую систему, поскольку адаптивность, наличие обратной связи и развитых связей с внешней средой характерно для подавляющего большинства экономических систем любого уровня.

В дальнейшем в качестве базового определения ЛС будем использовать приведенное в работе [15]: логистическая система - это совокупность подсистем: генерирующей, перемещающей и поглощающей материальный поток, согласованное функционирование которых на базе экономической, технической и технологической интеграции позволяет оптимизировать поступление материальных ценностей с определенными качественными и количественными характеристиками в определенное время и место определенному потребителю с определенным уровнем затрат. ЛС, 
как временно созданное предприятие по перемещению конкретного материального потока, в результате своей деятельности, при воздействии соответствующих ресурсов [16], создаёт продукт ЛС. Под продуктом логистической системы (ПЛС) будем понимать материальную ценность с требуемыми характеристиками (параметрами), получаемую путем преобразования логистических ресурсов в процессах логистической деятельности [17].

Под логистической услугой будем понимать комплекс услуг, оказываемых материальному производству, субъектам хозяйствования различных направлений деятельности и индивидам в виде логистических процедур и операций, осуществляемых при управлении потоковыми процессами в соответствии с правилами логистики.

Если рассматривать ЛС, включающую подсистемы закупки, хранения, распределения и, иногда, производство, материальная ценность формируется из интеграции логистических услуг в сфере закупок, хранения, транспортировки (которая возникает между каждой подсистемой), распределения и производства. В такой ЛС логистические услуги по функциональному назначению могут быть классифицированы следующим образом (рис.1).

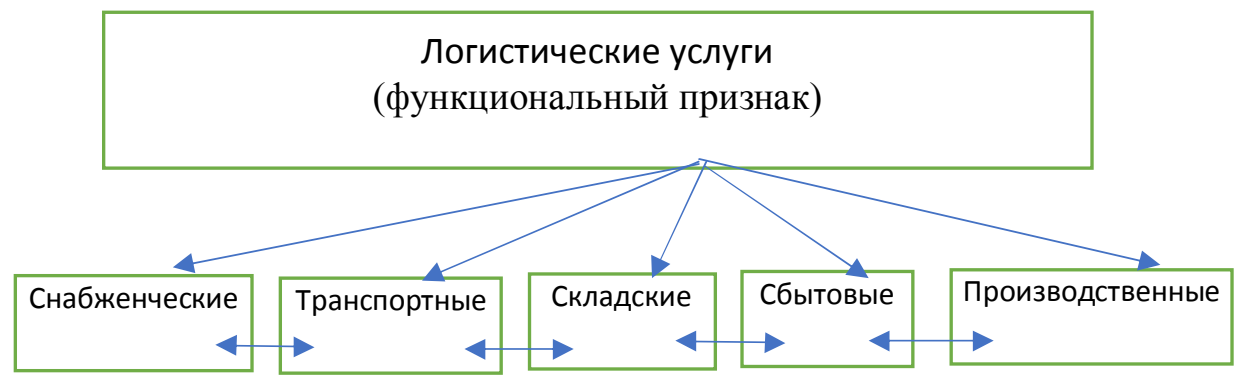

\section{Рис. 1. Классификация логистических услуг по функииональному признаку}

Необходимо отметить, что несмотря на то, что все составляющие в данном классификационном признаке являются паритетными, транспортная составляющая, с нашей точки зрения, вносит больший вклад в формирование ценности продукта ЛС. Это объясняется тем, что именно транспортная составляющая является связующим звеном между всеми подсистемами, а также внутри подсистем между их элементами. И, как отмечается, например в [2], затраты на транспортировку могут составлять до $70 \%$ от стоимости готового продукта.

Рассмотрим подробнее транспортно-логистическую услугу. Под транспортно- логистической услугой принято понимать комплекс операций, связанных, как с перемещением товаров (грузов), так и с определе- 
нием вида необходимого транспорта, разработкой оптимального маршрута, оформлением документов, консультационным сопровождением потребителей логистических услуг. Иначе говоря, транспортно-логистическая услуга включает в себя, в том числе, такие операции как, например, погрузка и выгрузка. Согласно [17; 18] под логистической операцией понимают обособленную совокупность действий, направленных на преобразование материального и (или) информационного потока (складирование, транспортировка, комплектация, погрузка, разгрузка, внутреннее перемещение: сбор, хранение и обработка данных и т.д.).

В то же время существует термин «грузовые операции», который, в соответствии с $[17 ; 19]$, в общем случае трактуется как операции по транспортировке, взвешиванию или иному определению количества товаров, погрузке, выгрузке, перегрузке, исправлению поврежденной упаковки, вскрытию упаковки и т.д.

Из представленных определений можно сделать вывод, что определения «логистические» и «грузовые» операции являются гомологичными. Исходя из этого, под логистической операщией будем понимать совокупность экономически, технически и технологически согласованных операций (складирование, транспортировка, комплектация, погрузка, разгрузка, перевалка, внутреннее перемещение: сбор, хранение и обработка данных и т.д.), направленных на материальный, и сопутствующие информационный и финансовый потоки, связывающие генерирующую, перемещающую и поглощающую подсистемы внутри ЛС с целью оптимизации перемещения материального потока с заданными качественными и количественными характеристиками. Иными словами, операции, выполняемые между подсистемами ЛС, а также внутри подсистем, являются логистическими, а требование выполнения этих операций внутри ЛС предполагает их интеграцию.

Известно, что любая ЛС формируется при возникновении необходимости перемещения материального потока в системах поставок, производства (хранения) или распределения. Поэтому справедливо считать, что именно материальный поток инициирует создание ЛС. По пути перемещения материальный поток может преобразовываться с помощью производственных или логистических операций. Так, в подсистеме производства на материальный поток воздействуют производственные операции, увеличивающие качественные характеристики; в подсистемах снабжения перемещения и распределения - логистические, которые, по сути, либо перемещают его, либо укрупняют, разукрупняют или переформировывают.

Таким образом, с помощью логистических операций происходит перемещение материального потока в соответствии требованиями потребителей. А выбор оптимальных логистических операций на пути его географического перемещения формирует оптимальный маршрут. Иначе говоря, между источником и стоком может быть построено конечное 
число маршрутов с различными временными и стоимостными характеристиками, отличающихся не только видом транспортных средств, участвующих в системе доставки (исходя из географического расположения), но и путем выбора альтернативных логистических операций, за счет, например, привлечения конкурирующих компаний, оказывающих соответствующие услуги.

Для построения оптимального или наилучшего маршрута с учетом рассмотрения всех технически и технологически возможных логистических операций на рассматриваемом направлении, необходимо явно прописать все операции, их стоимостные и временные характеристики. В нашем случае предлагается определить возможные маршруты с указанием стоимости и времени доставки с помощью сетевого планирования (графика). Сетевой график представляет собой систему узлов, связанную ориентированными дугами. Каждый узел обозначает соответствующее действие или логистическую операцию, а дуги связывающие узлы - время или стоимость выполнения операций.

В работе [13] рассматривается технология построения сетевого графика доставки груза в смешанном сообщении. Отметим, что реализация на практике данной технологии приводит к значительным затратам времени. Это связано с тем, что для описания всех возможных маршрутов необходимо последовательно осуществить перебор представленных операций, выполняемых для перемещения материального потока и далее методом прямого счета рассчитать время и затраты по каждому маршруту с целью выбора того, где либо затраты, либо время минимальное.

Предлагаем для решения задачи нахождения маршрута доставки путем выбора наилучших логистических операций, использовать задачу линейного программирования о «кратчайшем пути». При условии внесения модификаций она может быть сведена к сетевой постановке [20]. Модификация состоит в следующем:

1. Переменную $x_{i k}$, традиционно описывающую величину потока, представим как участок сети, выходящий из узла $i$ и входящий в узел $k$. В результате решения задачи будут определены участки сети, из которых складывается оптимальный маршрут.

2. Переменные $x_{i k}$, ранее принимающие только положительные значения, предлагаем считать булевыми, т.е. принимающими значение 0 либо 1: $x_{i k} \in\{0,1\}$. Если $x_{i k}=1$, соответствующий участок сети входит в формирование маршрута, если $x_{i k}=0$-участок не входит в маршрут.

Модель линейного программирования для задачи о кратчайшем пути строится следующим образом.

1. Каждая переменная $x_{i k}$ описывает стоимостные (временные) затраты при перемещении от $i$-го к $k$-му узлу и соответствует дуге. 
2. Каждое ограничение соответствует узлу (промежуточному пункту или логистической операции).

$$
\begin{gathered}
Z=\sum_{i=1}^{n} \sum_{k=1}^{n} c_{i k} x_{i k} \rightarrow \min \\
\sum_{i=1}^{n} x_{i k}=1 \\
\sum_{i=1}^{n} x_{i n}=1 \\
\sum_{k=1}^{n} x_{i k}-\sum_{i=1}^{n} x_{k i}=0(\forall i \in\{2, \ldots, n-1\}) \\
x_{i k} \in\{0,1\} ;(\forall i, k \in\{2, \ldots, n\})
\end{gathered}
$$

Поясним смысл целевой функции и ограничений:

(1) - целевая функция, минимизирующая затраты при формировании маршрута;

(1) - требование, чтобы искомый путь начинался в вершине 1 ;

(3) - требование чтобы искомый путь заканчивался в вершине $n$;

(4) - требование, чтобы искомый путь был связанным, то есть проходил через вершины графа;

(5) - требование, чтобы все переменные модели были булевыми.

Заметим, что представленная модель позволяет исследовать транспортную сеть на предмет построения маршрута как по критерию минимизации общих стоимостных затрат, так и минимизации времени, путем замены в целевой функции коэффициентов, характеризующих время доставки на соответствующих дугах. При этом будут получены маршруты, отличающиеся видом транспорта, используемого для доставки и, соответственно, логистическими операциями. Еще одним преимуществом применения модели является возможность определения времени доставки груза. Если целевой установкой выбора маршрута была минимизация общих стоимостных затрат на выполнение логистических операций, то методом простого суммирования затрат времени на полученных участках сети можно получить время выполнения контракта по доставке груза.

На примере доставки автомобилей с пробегом из США в Украину приведем алгоритм построения сети логистических операций и, используя предложенную экономико-математическую модель, определим оптимальный маршрут, учитывающий общие стоимостные и временные затраты.

Украинский автомобильный рынок за последние годы претерпел значительные структурные изменения. По данным «Укравтопром» [21] количество импортированных автомобилей за период с января по сентябрь 2019 года увеличилось. Так, за девять месяцев в Украину было 
ВІСНИК

ОДЕСЬКОГО НАЦІОНАЛЬНОГО

МОРСЬКОГО УНІВЕРСИТЕТУ № 3 (63), 2020
HERALD

OF THE ODESSA NATIONAL

MARITIME UNIVERSITY № 3 (63), 2020

импортировано почти 413000 легковых автомобилей. Из числа ввезенных автомобилей новых - 65300 транспортных средств, что составило около $16 \%$ от всего количества.

По сравнению с аналогичным периодом 2018 года импорт новых авто увеличился на $17 \%$, а подержанных в 3,8 раза больше. Высокий спрос на подержанные автомобили можно объяснить ценой и либерализацией условий ввоза. С ноября 2018 года действует закон № 2611-VIII о внесении изменений в Налоговый кодекс относительно налогообложения акцизным налогом легковых транспортных средств [22]. Согласно с данным документом существенно снизился размер акциза и появилась возможность растаможивать автомобили возрастом 10-15-20 и более лет.

Импортерами - лидерами продаж легковых автомобилей в 2019 году стали [23]: Германия - \$334,318 млн, Япония - \$245,863 млн, США $\$ 207,116$ млн. Если же рассмотреть сегмент рынка подержанных автомобилей, то согласно статистическим данным [24] в 2019 году доля завезенных автотранспортных средств из США составила 80 \%. Важным преимуществом американских автотранспортных средств является сравнительно молодой возраст, небольшой пробег, хорошее состояние и основная причина - низкая цена. Экономия на покупке авто из США может достигать 60 \% в сравнении с ценами на рынке Украины.

Известно, что цена автомобиля в Украине складывается не только из непосредственно оплаты за автомобиль, но и из логистических затрат на осуществление его доставки. Поэтому в настоящее время актуальным является вопрос выбора автомобиля на аукционе, его доставка конечному потребителю оговоренного качества, в оговоренное время и по возможно минимальной цене. Как показывает практика, такие требования могут быть выполнены, если процесс доставки будет основываться на логистическом подходе, т.е. при единой организации, управлении и контроле всеми операциями процесса закупки и доставки.

В настоящее время существует большое количество компаний и агентов, специализирующихся на доставке автомобилей из США. В основном доставка осуществляется по наработанным маршрутам, без учета предложений привлечения потенциальных посредников, оказывающих конкурирующие логистические услуги.

Покупка автомобиля начинается с обращения клиента к компании (агенту) с указанием желаемых характеристик, заканчивается - передачей желаемого автомобиля потребителю. Разработан обобщенный алгоритм (рис. 2) по осуществлению контракта покупки и доставки.

Как видно, в алгоритме прописана последовательность действий и логистические операции, возникающее в процессе покупки и доставки автомобиля. Выполнение этих операций влияет на время и стоимость покупки и доставки. Рассмотрены возможные варианты доставки как по наземному и морскому, так и по воздушному маршрутам. 
ВІСНИК

ОДЕСЬКОГО НАЦІОНАЛЬНОГО

МОРСЬКОГО УНІВЕРСИТЕТУ

№ 3 (63), 2020
HERALD

OF THE ODESSA NATIONAL

MARITIME UNIVERSITY № 3 (63), 2020

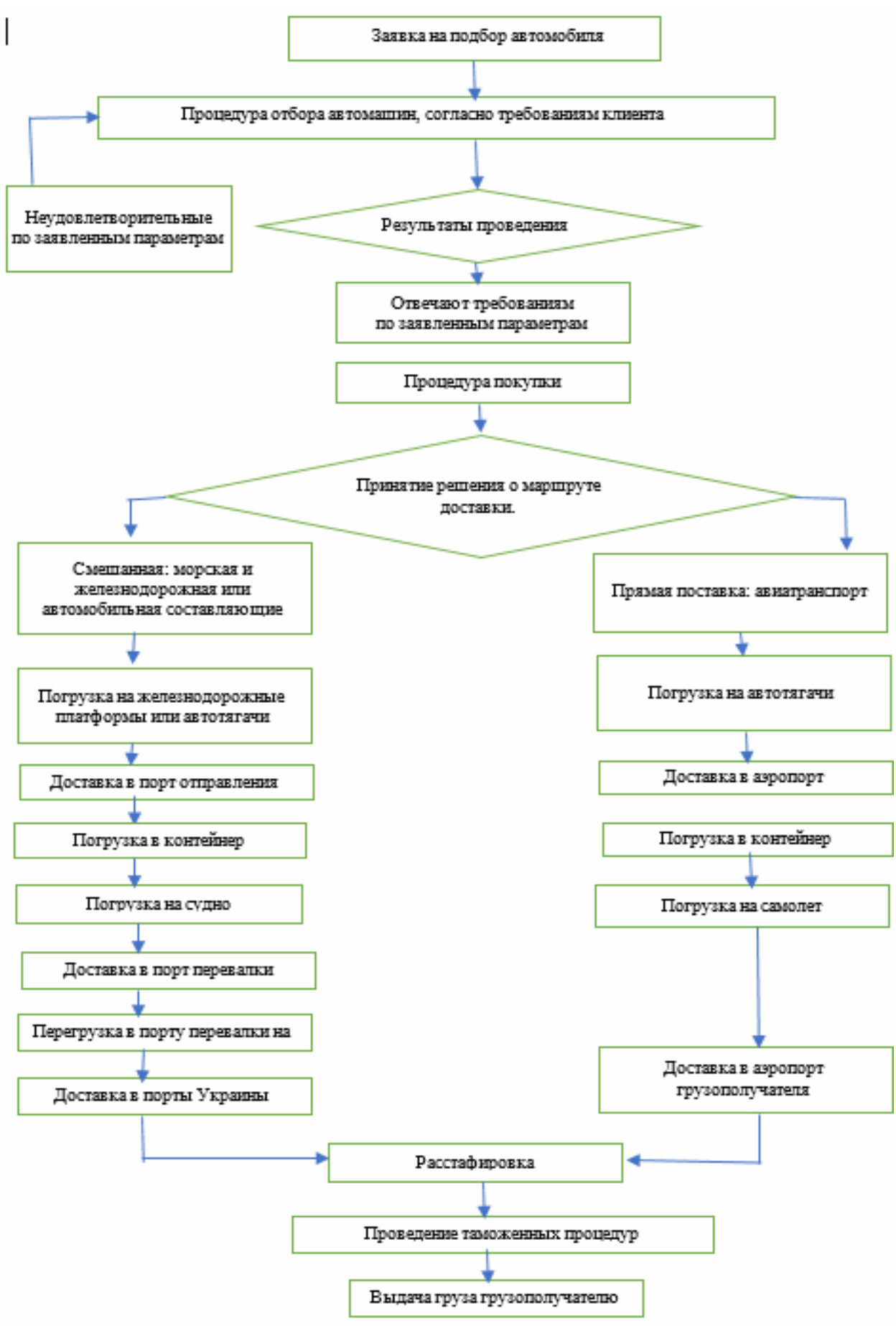

Рис. 2. Алгоритм доставки автомашин из США в Украину 
Предположим, что для покупки были выбраны автомобили на аукционах в штатах Луисвилл и Миннеаполис. Тогда, следуя транспортной инфраструктуре США, можно построить следующую схему доставки (рис. 3).

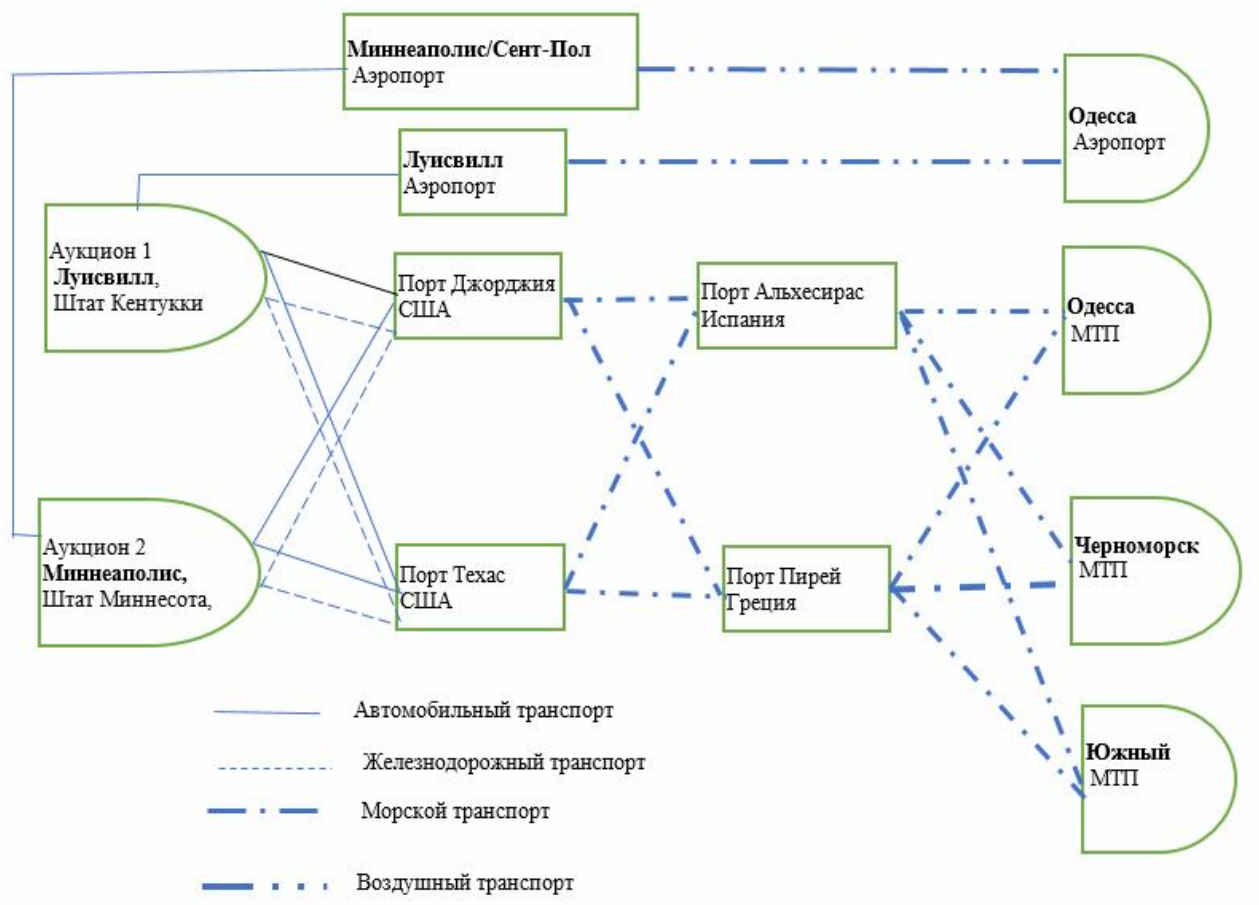

Рис. 3. Географическая схема возможных маршрутов доставки автомобилей

Итак, процесс доставки состоит из последовательности привлечения различных видов транспорта с промежуточной перевалкой. Проведенный анализ построенной схемы, с учетом возможных логистических операций, позволяет перейти к построению сетевого графика, представляющего собой альтернативные маршруты доставки (рис. 4). Количество возможных маршрутов определяется количеством узлов и дуг. Характеристику дуг, входящих в сетевой график приведем в таблице 1, где $i-$ начало дуги, номер узла из которого она выходит, а $k$ - конец дуги, номер узла, в который она входит.

Маршруты строят путем перебора всех связных узлов ориентированными дугами от источника к стоку. В рассматриваемом примере количество маршрутов, отличающихся составом логистических операций и привлеченных видов транспорта, составило 104.

Согласно [13], далее по всем маршрутам последовательно просчитываются стоимостные и временные характеристики. 
ВІСНИК

ОДЕСЬКОГО НАЦІОНАЛЬНОГО МОРСЬКОГО УНІВЕРСИТЕТУ
HERALD

OF THE ODESSA NATIONAL

MARITIME UNIVERSITY № 3 (63), 2020

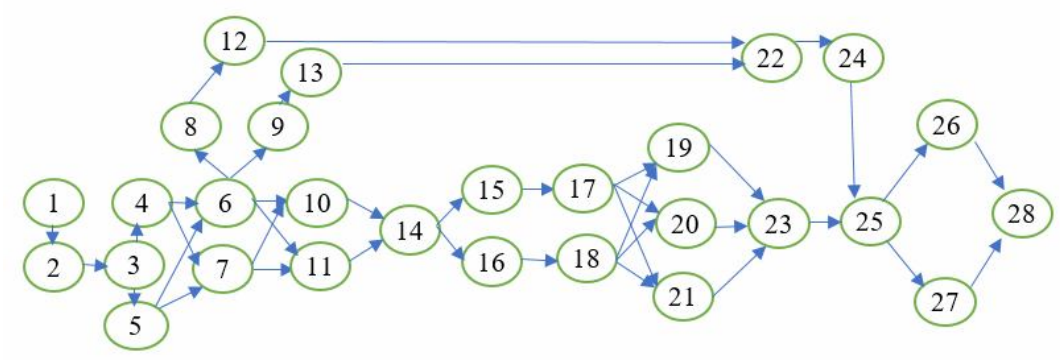

Рис. 4. Сетевой график доставки автомобилей из США в Украину

Таблица 1

Характеристика показателей по дугам, входящим в сетевой график

\begin{tabular}{|c|c|c|c|c|}
\hline \multicolumn{2}{|c|}{ Дуги } & \multirow{2}{*}{ Характеристика работы } & \multirow{2}{*}{$\begin{array}{c}\text { Стоимость, } \\
\$\end{array}$} & \multirow{2}{*}{$\begin{array}{l}\text { Время } \\
\text { (дней) }\end{array}$} \\
\hline$i$ & $k$ & & & \\
\hline 1 & 2 & 3 & 4 & 5 \\
\hline 1 & 2 & Поступление заявки на приобретение & 500 & 0,2 \\
\hline 2 & 3 & $\begin{array}{l}\text { Выбор на аукционе согласно требованию } \\
\text { клиента }\end{array}$ & 10 & 14 \\
\hline 3 & 4 & $\begin{array}{l}\text { Покупка и оформление документов } \\
\text { в Луисвилл }\end{array}$ & 2300 & 2 \\
\hline 3 & 5 & $\begin{array}{l}\text { Покупка и оформление документов } \\
\text { в Миннеаполис }\end{array}$ & 2300 & 2 \\
\hline 4 & 6 & Погрузка на автовоз в Луисвилл & 100 & 2 \\
\hline 4 & 7 & Погрузка на ж/д платформу в Луисвилл & 200 & 3 \\
\hline 5 & 6 & Погрузка на автовоз в Миннеаполис & 150 & 2 \\
\hline 5 & 7 & Погрузка на ж/д платформу в Миннеаполис & 230 & 3 \\
\hline 6 & 8 & Доставка автовозом в аэропорт Луисвилл & 300 & 1 \\
\hline 6 & 9 & Доставка автовозом в аэропорт Миннеаполис & 350 & 1 \\
\hline 6 & 10 & Доставка автовозом в порт Джорджия & 500 & 7 \\
\hline 6 & 11 & Доставка автовозом в порт Техас & 700 & 9 \\
\hline 7 & 10 & Доставка на ж/д платформе в порт Джорджия & 620 & 9 \\
\hline 7 & 11 & Доставка на ж/д платформе в порт Техас & 930 & 13 \\
\hline 8 & 12 & $\begin{array}{l}\text { Погрузка в контейнер и в самолет } \\
\text { в аэропорту Луисвилл }\end{array}$ & 120 & 0,5 \\
\hline 9 & 13 & $\begin{array}{l}\text { Погрузка в контейнер и в самолет } \\
\text { в аэропорту Миннеаполис }\end{array}$ & 115 & 0,5 \\
\hline 10 & 14 & $\begin{array}{l}\text { Погрузка в контейнер и на судно } \\
\text { в порту Джорджия }\end{array}$ & 125 & 3 \\
\hline 11 & 14 & $\begin{array}{l}\text { Погрузка в контейнер и на судно } \\
\text { в порту Техас }\end{array}$ & 140 & 2 \\
\hline 12 & 22 & Доставка в аэропорт Одесса & 15000 & 1 \\
\hline 13 & 22 & & 18000 & 1,2 \\
\hline
\end{tabular}


ВІСНИК

ОДЕСЬКОГО НАЦІОНАЛЬНОГО МОРСЬКОГО УНІВЕРСИТЕТУ № 3 (63), 2020
HERALD

OF THE ODESSA NATIONAL

MARITIME UNIVERSITY № 3 (63), 2020

Продолжение табл. 1

\begin{tabular}{|c|c|c|c|c|}
\hline 1 & 2 & 3 & 4 & 5 \\
\hline 10 & 14 & $\begin{array}{l}\text { Погрузка в контейнер и на судно } \\
\text { в порту Джорджия }\end{array}$ & 125 & 3 \\
\hline 11 & 14 & $\begin{array}{l}\text { Погрузка в контейнер и на судно } \\
\text { в порту Техас }\end{array}$ & 140 & 2 \\
\hline 12 & 22 & \multirow{2}{*}{ Доставка в аэропорт Одесса } & 15000 & 1 \\
\hline 13 & 22 & & 18000 & 1,2 \\
\hline 14 & 15 & Доставка в порт Альхесирас & 400 & 11 \\
\hline 14 & 16 & Доставка в порт Пирей & 600 & 16 \\
\hline 15 & 17 & ПРР в порту Альхесирас & 130 & 3 \\
\hline 16 & 18 & ПРР в порту Пирей & 110 & 4 \\
\hline 17 & 19 & Доставка из Альхесирас в порт Одесса & 380 & 17 \\
\hline 17 & 20 & Доставка из Альхесирас в порт Черноморск & 330 & 17 \\
\hline 17 & 21 & Доставка из Альхесирас в порт Южный & 350 & 15 \\
\hline 18 & 19 & Доставка из Пирея в порт Одесса & 260 & 12 \\
\hline 18 & 20 & Доставка из Пирея в порт Черноморск & 230 & 11 \\
\hline 18 & 21 & Доставка из Пирея в порт Южный & 250 & 12 \\
\hline 19 & 23 & \multirow{3}{*}{$\begin{array}{l}\text { Расстафировка в терминалах } \\
\text { МТП Украины }\end{array}$} & \multirow{3}{*}{500} & \multirow{3}{*}{1} \\
\hline 20 & 23 & & & \\
\hline 21 & 23 & & & \\
\hline 22 & 24 & Расстафировка в аэропорту Одесса & 250 & 0,5 \\
\hline 24 & 25 & $\begin{array}{l}\text { Растаможка в терминале аэропорта } \\
\text { Одесса }\end{array}$ & 1600 & 14 \\
\hline 23 & 25 & Растаможка в терминале МТП Украины & 1600 & 14 \\
\hline 25 & 26 & Выезд с терминала своим ходом & 10 & 0.5 \\
\hline 25 & 27 & Выезд с терминала эвакуатором & 10 & 1 \\
\hline 26 & 28 & \multirow{2}{*}{$\begin{array}{l}\text { Выдача автомобиля и закрытие } \\
\text { контракта }\end{array}$} & \multirow{2}{*}{10} & \multirow{2}{*}{1} \\
\hline 27 & 28 & & & \\
\hline
\end{tabular}

Предлагаем поиск оптимального маршрута провести с использованием модели (1-5), что значительно упрощает процесс принятия решения, исключая трудоемкую операцию перебора возможных маршрутов на рис. 4.

Экономико-математическая модель сетевого графика (рис.4) для критерия минимизации общих затрат в числовом виде имеет вид (6-10)

$$
\begin{aligned}
& Z=500 x_{12}+10 x_{23}+2300 x_{34}+2100 x_{35}+100 x_{46}+200 x_{47}+150 x_{56}+300 x_{68}+ \\
& +230 x_{57}+350 x_{69}+500 x_{610}+700 x_{611}+620 x_{710}+930 x_{711}+120 x_{812}+115 x_{913}+(6) \\
& +125 x_{1014}+40 x_{1114}+1500 x_{1222}+1800 x_{1322}+400 x_{1415}+600 x_{1416}+1130 x_{1517}+ \\
& +110 x_{1618}+380 x_{1719}+330 x_{1721}+260 x_{1819}+230 x_{1820}+250 x_{1821}+500 x_{1923}+ \\
& +500 x_{2023}+500 x_{2123}+250 x_{2224}+1600 x_{2425}+10 x_{2526}+10 x_{2527}+10 x_{2628} \rightarrow \min
\end{aligned}
$$




$$
\begin{aligned}
& x_{12}=1 \\
& x_{12}-x_{23}=0 \\
& x_{23}-x_{34}-x_{35}=0 \\
& x_{34}-x_{46}-x_{47}=0 \\
& x_{35}-x_{56}-x_{57}=0 \\
& x_{46}+x_{56}-x_{610}-x_{611}=0 \\
& x_{47}+x_{57}-x_{710}-x_{711}=0 \\
& x_{68}-x_{812}=0 \\
& x_{69}-x_{913}=0 \\
& x_{610}+x_{710}-x_{1014}=0 \\
& x_{611}+x_{711}-x_{1114}=0 \\
& x_{812}-x_{1222}=0 \\
& x_{913}-x_{1322}=0 \\
& x_{1014}+x_{1114}-x_{1415}-x_{1416}=0 \\
& x_{1415}-x_{1517}=0 \\
& x_{1416}-x_{1618}=0 \\
& x_{1517}-x_{1719}-x_{1720}-x_{1721}=0 \\
& x_{1618}-x_{1819}-x_{1820}-x_{1821}=0 \\
& x_{1719}+x_{1819}-x_{1923}=0 \\
& x_{1720}+x_{1820}-x_{2023}=0 \\
& x_{1721}+x_{1821}-x_{2123}=0 \\
& x_{1222}+x_{1322}-x_{2224}=0 \\
& x_{1923}+x_{2023}+x_{2123}-x_{2325}=0 \\
& x_{2224}-x_{2425}=0 \\
& x_{2325}+x_{2425}-x_{2526}-x_{2527}=0 \\
& x_{2526}-x_{2628}=0 \\
& x_{2527}-x_{2728}=0 \\
& x_{2628}+x_{2728}=1 \\
x_{i k} \in\{0,1\} ; & (\forall i, k \in\{1,2, \ldots, 28\}) \\
&
\end{aligned}
$$

Решение задачи проводилось при использовании Microsoft Office Excel, в программной надстройке «Поиск решения».

В результате решения получены единичные значения следующих переменных:

$$
x_{12}, x_{13}, x_{35}, x_{56}, x_{610}, x_{1014}, x_{1415}, x_{1517}, x_{1720}, x_{2023}, x_{2325}, x_{2527}, x_{2728},
$$


указывающих на цепочку операций, из которых складывается оптимальный маршрут.

Интерпретируем полученное решение. С момента поступления заявки агент из двух аукционов оформляет покупку в Миннеаполисе, затем осуществляет погрузку на автовоз и доставляет в Порт Джорджия, где осуществляется стафировка автомобиля в контейнер. Из порта Джорджия на морском судне контейнер доставляется в порт Альхесирас, где он перегружается на другое судно и доставляется в порт Черноморск. В Черноморске производятся операции по расстафировке контейнера и прохождению таможенных формальностей. Выезд из порта автомобиля осу-ществляется эвакуатором. Общие затраты на доставку, с учетом коммерческих, как торговых операций купли - продажи и логистических операций составляют 6356 долл. Не трудно заметить, что затраты на выполнение этих операций почти в 2 раза превышают стоимость самого товара, что еще раз подчеркивает актуальность их оптимизации при выполнении каждого контракта.

Поскольку время в ЛС является одним из важнейших показателей, выполним его расчет для полученного маршрута. Для этого воспользуемся таблицей 1 и путем суммирования показателя времени для соответствующих оптимальных переменных найдем значение этого показателя.

$$
\begin{aligned}
& T=t_{12}+t_{13}+t_{35}+t_{56}+t_{610}+t_{1014}+t_{1415}+t_{1517}+t_{1720}+t_{2023}+t_{2325}+t_{2527}+t_{2728}= \\
& =0,2+14+2+2+7+3+11+3+17+1+14+1+1=79, \text { суток }
\end{aligned}
$$

Не исключено, что клиент может выставить требование доставки автомобиля в кратчайшие сроки, независимо от возможного увеличения затрат. В таком случае в предложенной модели изменится только целевая функция, а точнее ее коэффициенты, характеризующие затраты времени по дугам.

$$
\begin{aligned}
& Z=0,2 x_{12}+14 x_{23}+2 x_{34}+2 x_{35}+2 x_{46}+3 x_{47}+2 x_{56}+3 x_{57}+1 x_{68}+1 x_{69}+7 x_{610}+ \\
& +9 x_{611}+9 x_{710}+13 x_{711}+0,5 x_{812}+0,5 x_{913}+3 x_{1014}+2 x_{1114}+1 x_{1222}+1,2 x_{1322}+ \\
& +11 x_{1415}+16 x_{1416}+3_{1517}+4 x_{1618}+17 x_{1719}+15 x_{1721}+12 x_{1819}+11 x_{1820}+12 x_{1821}+ \\
& +1 x_{1923}+1 x_{2023}+1 x_{2123}+0,5 x_{2224}+14 x_{2425}+14 x_{2526}+0,5 x_{2527}+5 x_{2628} \rightarrow \text { min }
\end{aligned}
$$

В результате пересчета по времени получены следующие оптимальные участки цепи (дуги)

$$
x_{12}, x_{23}, x_{34}, x_{46}, x_{68}, x_{812}, x_{1222}, x_{2224}, x_{2425}, x_{2526}, x_{2628},
$$

что означает покупку автомобиля в Луисвилле, доставку автомобиля на автовозе в аэропорт Луисвилл, стафировку в контейнер и отправку в аэропорт Одесса, где происходит расстафировка контейнера, прохождение 
таможенных формальностей и выезд автомобиля с терминала аэропорта собственным ходом, с последующей передачей автомобиля владельцу и закрытием контракта. При таком варианте время доставки составило 36,7 суток, а стоимость - 20200 долл. Т.е. сокращение времени доставки почти в 2 раза, привело к увеличению стоимости доставки примерно в 3 раза.

Результаты применения экономико-математической модели в решении подобных задач являются основой для принятия решения о выборе маршрута доставки, исходя из требований клиента.

Отметим, что в результате решения был получен оптимальный маршрут доставки и покупки одного автомобиля. Это означает, что модель не учитывает общие и временные затраты на приобретение и доставку партии автомобилей, а простое умножение этих затрат на предполагаемое количество закупаемых автомобилей может привести к ошибочным результатам. Поскольку при доставке на некоторых участках используется контейнеры, куда может быть застафировано 2 автомобиля, то затраты на выполнения операций рассчитываются с учетом укрупнения грузовой единицы. С целью решения данного вопроса предлагаем рассмотреть модель многоэтапной транспортной задачи, но с учетом внесения изменений, учитывающих сетевую постановку, возможность прямой доставки и использования нескольких видов транспорта.

Пусть необходимо доставить автомобили из США в Украину для компании, осуществляющей их оптовую покупку, с целью удовлетворения массовых заказов потребителей.

Поскольку, затраты на покупку и доставку не единственные, из которых складывается цена на автомобиль, при построении логистической системы, точкой инициации (источником) ее будем считать момент подачи заявки на покупку, а стоком - выдачу автомобиля потребителю. Таким образом, исходя из рисунков 3 и 4, формируются маршруты, учитывающие выбор логистических операций. Особенностью моделирования задачи в указанной постановке является наличие одного источника и стока. Выбор аукциона (как поставщика) в любом из штатов, вида транспорта или альтернативной операции, разветвляет сеть (рис. 4), формируя возможные варианты маршрута.

Итак, экономико-математическая модель задачи построения логистической системы доставки с учетом выбора поставщика, логистических и коммерческих операций будет иметь вид

$$
\begin{gathered}
Z=\sum_{i=1}^{I} \sum_{k=1}^{K} \sum_{z=1}^{Z} c_{i k}^{z} x_{i k}^{z}+\sum_{k=1}^{K} \sum_{l=1}^{L} c_{k l} x_{k l}+\sum_{l=1}^{L} \sum_{j=1}^{J} \sum_{z=1}^{Z} c_{l j}^{z} x_{l j}^{z}+\sum_{i=1}^{I} \sum_{j=1}^{J} c_{i j} x_{i j} \rightarrow \min \\
\sum_{k=1}^{K} \sum_{z=1}^{Z} x_{i k}^{z}+\sum_{j=1}^{J} x_{i j}=Q(i=\overline{1, I}) \\
\sum_{i=1}^{I} \sum_{z=1}^{Z} x_{i k}^{z}=\sum_{l=1}^{L} x_{k l}(k=\overline{1, K} ; i=\overline{1, I})
\end{gathered}
$$




$$
\begin{gathered}
\sum_{k=1}^{K} x_{k l}=\sum_{l=1}^{L} \sum_{z=1}^{Z} x_{l j}^{z}(j=\overline{1, J}) \\
\sum_{l=1}^{L} \sum_{z=1}^{Z} x_{l j}^{z}+\sum_{i=1}^{I} x_{i j}=Q(j=\overline{1, J}) \\
x_{i k}^{z} \geq 0(i=\overline{1, I} ; k=\overline{1, K} ; z=1, Z) ; x_{k l} \geq 0(k=\overline{1, K} ; l=\overline{1, L}) \\
x_{l j}^{z} \geq 0(l=\overline{1, L} ; j=\overline{1, J} ; z=1, Z) ; x_{i j} \geq 0(i=\overline{1, I} ; j=\overline{1, J})
\end{gathered}
$$

Смысл параметра управления - объем перевозки груза на рассматриваемых этапах. Затратные характеристики формируются по этапам согласно сетевому графику и географической схемы доставки (рис. 3 и 4).

$c_{i k}^{z}$ - затраты, связанные с оформлением заявки, выбором аукциона, участием в аукционе, непосредственной покупкой, погрузоразгрузочными работами и доставкой автомобильным или железнодорожным видом транспорта до портов отправления.

$$
x_{i k}^{z} \text { - количество автомобилей, перемещаемых на этом (I) этапе. }
$$

Так, например, значение $C_{11}^{1}$, согласно таблице 1 , будет определяться суммированием значений, соответствующих дугам 1-2, 2-3, 3-4, 4-6, 6-10.

$$
C_{11}^{1}=500+10+2300+100+500=3410 \text { долл. }
$$

Цепочки дуг, формирующие возможные маршруты на I тапе приведены в таблице 2.

Таблица 2

Цепочки дуг, определяющих затрать на доставку (I этап)

\begin{tabular}{|c|c|c|c|}
\hline Затраты & Дуги & Затраты & Дуги \\
\hline$C_{11}^{1}$ & $1,2,3,4,6,10$ & $C_{21}^{1}$ & $1,2,3,5,6,10$ \\
\hline$C_{11}^{2}$ & $1,2,3,4,7,10$ & $C_{21}^{2}$ & $1,2,3,5,7,10$ \\
\hline$C_{12}^{1}$ & $1,2,3,4,6,11$ & $C_{22}^{1}$ & $1,2,3,5,6,11$ \\
\hline$C_{12}^{2}$ & $1,2,3,4,7,11$ & $C_{22}^{2}$ & $1,2,3,5,7,11$ \\
\hline
\end{tabular}

$c_{k l}$ - затраты на II этапе, включающие операции: стафировку в контейнер, погрузо-разгрузочные работы в портах отправления и прибытия, $x_{k l}$-количество автомобилей, сталированных в контейнер. 
Таблица 3

Цепочки дуг, определяющих затраты на доставку (II этап)

\begin{tabular}{|c|c|c|c|}
\hline Затраты & Дуги & Затраты & Дуги \\
\hline$C_{11}^{1}$ & $10,14,15,17$ & $C_{12}^{1}$ & $11,14,15,17$ \\
\hline$C_{21}^{1}$ & $10,14,16,18$ & $C_{22}^{1}$ & $11,14,16,18$ \\
\hline
\end{tabular}

$c_{l j}^{z}$ - затраты на III этапе, включающие операции по доставке из портов перевалки в порты Украины, растафировку контейнера на терминале (морском), таможенные операции, выезд с терминала собственным ходом или при помощи эвакуатора.

$$
x_{l j}^{z} \text { - количество автомобилей, перемещаемых на III этапе. }
$$

Таблица 4

Цепочки дуг, определяющих затраты на доставку (III этап)

\begin{tabular}{|c|c|c|c|c|c|}
\hline Затраты & Дуги & Затраты & Дуги & Затраты & Дуги \\
\hline$C_{11}^{1}$ & $17,19,24,25,26,28$ & $C_{12}^{1}$ & $17,20,24,25,26$ & $C_{12}^{1}$ & $17,21,24,25,26$ \\
\hline$C_{11}^{2}$ & $17,19,24,25,27,28$ & $C_{12}^{2}$ & $17,20,24,25,27$ & $C_{12}^{2}$ & $17,21,24,25,27$ \\
\hline$C_{21}^{1}$ & $18,19,24,25,26,28$ & $C_{22}^{1}$ & $18,20,24,25,26$ & $C_{22}^{1}$ & $18,21,24,25,26$ \\
\hline$C_{21}^{2}$ & $18,19,24,25,27,28$ & $C_{22}^{2}$ & $18,20,24,25,27$ & $C_{22}^{2}$ & $18,21,24,25,27$ \\
\hline
\end{tabular}

$c_{i j}$ - затраты на IV этапе (прямая поставка), включающие оформление заявки, выбор аукциона, участие в аукционе, непосредственную покупку, доставку до авиапорта, стафировку в контейнер и доставку в авиапорт Украины, расстафировку контейнера, проведение таможенных операций, выезд с терминала и выдачу автомобиля потребителю. $x_{i j}$ количество автомобилей, доставляемых по прямому варианту (авиатранспортом).

Таблица 5

Цепочки дуг, определяющих затраты на доставку (IV этап)

\begin{tabular}{|c|c|c|c|}
\hline Затраты & Дуги & Затраты & Дуги \\
\hline$C_{11}$ & $1,2,3,4,6,8,12,22,24,25,26,28$ & $C_{12}$ & $1,2,3,4,6,8,12,22,24,25,27,28$ \\
\hline$C_{21}$ & $1,2,3,5,6,9,13,22,24,25,26,28$ & $C_{22}$ & $1,2,3,5,6,9,13,22,24,25,27,28$ \\
\hline
\end{tabular}


Поясним содержание ограничений модели (13)-(18).

(13) - в качестве критерия оптимизации используется минимизация общих расходов на проведение логистических и коммерческих операций, возникающих при формировании логистической системы доставки.

(14) - количество закупаемого (на аукционах) и доставляемого груза по прямому и перевалочному вариантам должно соответствовать количеству, заявленному в контракте.

(15) - количество груза, доставленного в порт перевалки должно соответствовать количеству груза, вывезенного из соответствующего порта.

(16) - количество груза, доставленного порт назначения должно быть вывезено из него одним из возможных способов.

(17) - количество груза, доставленного по прямому и (или) перевалочному варианту должно соответствовать количеству, заявленному в контракте.

(18) - условие неотрицательности переменных.

Представленная экономико-математическая модель легко разрешима в Microsoft Office Excel. При введении Q=1, т.е. доставки 1 автомобиля, получено решение, аналогичное результатам по (1)-(5). Отметим так же что, основываясь на таблицах 1 и 2-5, несложно также просчитать время выполнения контракта.

Выводы. Высокая степень конкуренции среди компаний, оказывающих логистические услуги, привела к необходимости адаптации и разработки новых методов совершенствования системы доставки путем построения ЛС, учитывающих не только затраты на непосредственное перемещение, но и все коммерческие и логистические операции, посредством которых происходит формирование материального потока и его последовательное перемещение до потребителя.

В связи с этим в работе было уточнено определение понятия «логистические операции» и выявлена их роль в построении оптимальных маршрутов.

На примере доставки автомобилей из США в Украину построен алгоритм и сетевой график учета коммерческих и логистических операций при построении маршрута доставки. Адаптирована ранее известная и предложена новая экономико-математические модели, позволяющие выбрать оптимальные логистические и коммерческие операции, определяющие маршрут доставки. 
ВІСНИК

ОДЕСЬКОГО НАЦІОНАЛЬНОГО

МОРСЬКОГО УНІВЕРСИТЕТУ

№ 3 (63), 2020
HERALD

OF THE ODESSA NATIONAL

MARITIME UNIVERSITY

№ 3 (63), 2020

\section{СПИСОК ЛІТЕРАТУРИ}

1. Аникин Б.А. Логистика [Текст]: учебное пособие / Б.А. Аникин, Л.С.Федоров, Ю.Ю. Наймарк, В.И. Аксенов, Ю.В. Бобков, В.В. Дьбская, Е.А Медведев, С.К. Чудаков, О.В. Шуйская. М.: ИНФРА-М, 1999. 327 c.

2. Гаджинский А.М. Логистика [Текст]: учебник для высш. и средн. спеи. учеб. заведений / А.М. Гаджинский. М.: Маркетинг, 1998. $228 \mathrm{c}$.

3. Миротин Л.Б. Транспортная логистика [Текст]: Учебник / Л.Б. Миротин, Ы.Е. Тышбаев, В.А. Гудков, С.А. Некрасов, В.А. Курганов, А.В. Володин, Ань Вьет Нгуен, Е.С. Антипов, Н.С. Журавлева, Е.Ю. Куликова, А.А. Бульба. М.: Изд-во «Экзамен», 2003. $512 \mathrm{c}$.

4. Сергеев, В.И. Логистика в бизнесе [Текст]: Учебник / В.И. Сергеев. М.: ИНФРА-М, 2001. 608 с.

5. Воевудский, Е.Н. Экономико-математические методы и модели в управлении морским транспортом [Текст] / Е.Н. Воевудский, Н.А. Коневиева, Г.С. Махуренко, И.П. Тарасова; под ред. Е.Н. Воевудского. М.: Транспорт, 1986. $287 \mathrm{c}$.

6. Гольштейн Е.Г., Юдин Д.Б. Задачи линейного программирования транспортного типа. М.: Наука, 1969. 382 c.

7. Постан М.Я. Экономико-математические модели смешанных перевозок [Текст] / М.Я. Постан. Одесса: Астропринт, 2006. $376 c$.

8. Постан М.Я. Модель оптимального планирования производства и доставки продукиии предприятия по распределительным каналам [Текст] / М.Я. Постан, Д.А. Малиновский // Методи та засоби управління розвитком транспортних систем: 3б. наук. пращь ОНМУ, № 15, 2009. С. 19-28.

9. Поддубная Н.Н. Использование усложненных постановок транспортной задачи для обоснования логистических систем. [Текст] / Н.Н. Поддубная // Вісник Одеського наиіонального морського університету / 3б. наук. праиь. № 1(47). Одеса: OHMУ, 2016. C. 171-178.

10. Поддубная Н.Н. Экономико-математическая модель обоснования месторасположения логистических распределительных иентров при контейнерных перевозках. [Текст] / Н.Н. Поддубная // Вісник Одеського начіонального морського університету: 3б. наук. праиь. № 1(47). Одеса: ОНМУ, 2016. C. $165-170$. 
ВІСНИК

ОДЕСЬКОГО НАЦІОНАЛЬНОГО

МОРСЬКОГО УНІВЕРСИТЕТУ

№ 3 (63), 2020
HERALD

OF THE ODESSA NATIONAL

MARITIME UNIVERSITY

11. Poddybnaya, N.N., Udovitsa, O.O. Methodical main regulations of the optimization of the logistics delivery systems parameters with consideration of its transportation mode. [Текст] / Н.Н. Поддубная, О.О. Удовича // Вісник» Східноукрайнського національного університету ім. Володимира Даля: Зб. наук. праць. № 2(243). 2018. C. 20-26.

12. Поддубная Н.Н. Оптимізачія розтамування розподільних иентрів у логістичній підсистемі розподілу / Н.Н. Піддубна, А.В. Кирічок // Вісник Східноукрайнського начіонального університету ім. Володимира Даля: Наук. журнал. 2019. № 3 (251). C. 135-143.

13. Лукинский В.С. Модели и методы теории логистики [Текст]: Учебное пособие. 2-е изд. / В.С. Лукинский, В.В. Лукинский, Ю.В. Малевич, И.А. Пластуняк, Н.Г. Плетнева. СПб.: Питер, 2008. $448 \mathrm{c}$.

14. Бабурин B.A. Оптимизация параметров логистической системы доставки грузов. [Текст] / В.А. Бабурин, Н.В. Бабурин // Журнал университета водных коммуникаций. С. 121126.

15. Ляменко Н.И. Обоснование подхода к опредлениию логистической системы [Текст] / Н.И. Ляшенко // Розвиток методів управління та господарювання на транспорті: $3 б$. наук. праць. Одеса: ОНМУ, 2005. Вип. 23. C.151-158.

16. Лапкина И.А. Ресурсы логистической системы [Текст]/ И.А. Лапкина, Н.Н. Поддубная// Вестник СНУ им. В. Даля. 2015. № 2 (219). C. 69-72.

17. Поддубная Н.Н. Идентификаиия ресурсов и продукта проекта «логистическая система» // Технологический аудит и резервы производства. № 2/3 (28), 2016. 49-53.

18. Словарь терминов - Логистика. Т.И. Савенкова (2007). [Электронный ресурс]. - Режим доступа: https://www.xсотр. biz/slovar-terminov-savenkova-t-i.html

19. Основные понятия и термины в логистике [Электронный ресурс]. Режим достуnа: http://www.west-pereezd.su/osnovnyieponyatiya-i-terminyi-v-logistike.html

20. Словарь терминов и определений в логистике [Электронный ресурс]. Режим достуna: http://www.baif.by/stati/slovar terminov-i-opredelenii-v-logistike

21. Асламова В.С. Алгоритмы решения транспортных, сетевых задач и задач о назначении [Текст]: Учебное пособие. Ч. 2 я. / В.С. Асламова, И.М. Кулакова, М.Н. Колесник. Ангарск: АГТА, 2008. $190 \mathrm{c}$. 
22. Укравтопром [Электронный ресурс]. Режим доступа: http://ukrautoprom.com.ua/ru/za-rik-bilshe-408-tisyach-vzhivanixavto-popovnili-ukraïnskij-avtopark

23. Деньги.иа [Электронный ресурс]. Режим доступа: http:// dengi.ua/archive/articles/312441-Avto-s-probegom-prodajutpochti-darom

24. Уніан. Информационное агентство [Электронный ресурс]. Режим достуnа: https://www.unian.net/economics/transport/ 10631775-ukraincy-s-nachala-goda-kupili-inomarok-na-1-7milliarda.html

25. Finance.иа [Электронный ресурс]. Режим доступа: https:// news.finance.ua/ru/news/-/455524/amerikanskie-b-u-avtozavoevyvayut-rynok-za-chto-ukraintsy-polyubili-avto-iz-ssha

\section{REFERENCES}

1. Anikin, B.A. Logistika [Tekst]: uchebnoe posobie / B.A. Anikin, L.S. Fedorov, Yu.Yu. Najmark, V.I. Aksenov, Yu.V. Bobkov, V.V Dybskaya, E.A. Medvedev, S.K. Chudakov, O.V. Shujskaya. M.: INFRA-M, 1999. $327 \mathrm{~s}$.

2. Gadzhinskij, A.M. Logistika [Tekst]: uchebnik dlya vyssh. $i$ sred. spec. ucheb. zavedenij / A.M. Gadzhinskij. M.: Marketing, 1998. $228 \mathrm{~s}$.

3. Mirotin, L.B. Transportnaya logistika [Tekst]: Uchebnik / L.B. Mirotin, Y.E. Tyshbaev, V.A. Gudkov, S.A. Nekrasov, V.A. Kurganov, A.V. Volodin, An' V'et Nguen, E.S. Antipov, N.S. Zhuravleva, E.Yu. Kulikova, A.A. Bul'ba. M.: Izd-tvo «Ekzamen», 2003. $512 \mathrm{~s}$.

4. Sergeev, V.I. Logistika v biznese [Tekst]: uchebnik/V.I. Sergeev. M.: INFRA-M, 2001. 608 s.

5. Voevudskij, E.N. Ekonomiko-matematicheskie metody i modeli $v$ upravlenii morskim transportom [Tekst] / E.N. Voevudskij, N.A. Konevceva, G.S. Mahurenko, I.P. Tarasova; pod red. E.N. Voevudskogo. M.: Transport, 1986. 287 c.

6. Gol'shtejn, E.G., Yudin, D.B. Zadachi linejnogo programmirovaniya transportnogo tipa. M.: Nauka, 1969. $382 \mathrm{~s}$.

7. Postan, M.Ya. Ekonomiko-matematicheskie modeli smeshannyh perevozok [Tekst]. M.Ya. Postan. Odessa: Astroprint, 2006. 376 s.

8. Postan M.Ya. Model' optimal'nogo planirovaniya proizvodstva $i$ dostavki produkcii predpriyatiya po raspredelitel'nym kanalam [Tekst] / M.Ya. Postan, D.A. Malinovskij // Metodi ta zasobi upravlinnya rozvitkom transportnih sistem: Zb. nauk. prac' ONMU, № 15, 2009. S. 19-28. 
9. Poddubnaya, N.N. Ispol'zovanie uslozhnennyh postanovok transportnoj zadachi dlya obosnovaniya logisticheskih sistem. [Tekst] / N.N. Poddubnaya // Visnik Odes'kogo nacional'nogo mors'kogo universitetu: Zb. nauk. prac'. № 1(47). Odesa: ONMU, 2016. S. 171-178.

10. Poddubnaya, N.N. Ekonomiko-matematicheskaya model' obosnovaniya mestoraspolozheniya logisticheskih raspredelitel'nyh centrov pri kontejnernyh perevozkah. [Tekst] / N.N. Poddubnaya // Visnik Odes'kogo nacional'nogo mors'kogo universitetu: Zb. nauk. prac'. № 1(47). Odesa: ONMU, 2016. S. 165-170.

11. Poddybnaya, N.N., Udovitsa, O.O. Methodical main regulations of the optimization of the logistics delivery systems parameters with consideration of its transportation mode. [Tekst] / N.N. Poddubnaya, O.O. Udovica // Visnik» Skhidnoukraïns'kogo nacionalnogo universitetu im. Volodimira Dalya: Zb. nauk. prac' № 2(243). 2018. S. 20-26.

12. Poddubnaya, N.N. Optimizaciya roztashuvannya rozpodil'nih centriv v logistichnij pidsistemi rozpodilu / N.N.Piddubna, A.V. Kirichok // Visnik Skhidnoukrä̈n'kogo nacional'nogo universitetu im. Volodimira Dalya: Nauk. zhurnal. 2019. № 3 (251). S. 135-143.

13. Lukinskij, V.S. Modeli i metody teorii logistiki [Tekst]: Uchebnoe posobie. 2-e izd. / V.S. Lukinskij, V.V. Lukinskij, YU.V. Malevich, I.A. Plastunyak, N.G. Pletneva. SPb.: Piter, 2008. 448 s.

14. Baburin, V.A. Optimizaciya parametrov logisticheskoj sistemy dostavki gruzov. [Tekst] / V.A. Baburin, N.V. Baburin // Zhurnal universiteta vodnyh kommunikacij. S. 121-126.

15. Lyashenko, N.I. Obosnovanie podhoda $k$ opredleniiyu logisticheskoj sistemy [Tekst] / N.I. Lyashenko // Rozvitok metodiv upravlinnya ta gospodaryuvannya na transporti: Zb. nauk. prac'. Odesa: ONMU, 2005. Vip. 23. S. 151-158.

16. Lapkina, I.A. Resursy logisticheskoj sistemy [Tekst] / I.A. Lapkina, N.N. Poddubnaya // Vestnik CNU im. V. Dalya. 2015. № 2 (219). S. 69-72.

17. Poddubnaya, N.N. Identifikaciya resursov i produkta proekta «logisticheskaya sistema» // Tekhnologicheskij audit i rezervy proizvodstva. № 2/3 (28). 2016. 49-53.

18. Slovar' terminov - Logistika. T.I. Savenkova (2007). [Elektronnyj resurs]. Rezhim dostupa: https://www.xcomp.biz/slovar-termi-novsavenkova-t-i.html

19. Osnovnye ponyatiya i terminy $v$ logistike [Elektronnyj resurs]. Rezhim dostupa: http://www.west-pereezd.su/osnovnyie-ponyatiyai-terminyi-v-logistike.html 
ВІСНИК

ОДЕСЬКОГО НАЦІОНАЛЬНОГО

МОРСЬКОГО УНІВЕРСИТЕТУ № 3 (63), 2020
HERALD

OF THE ODESSA NATIONAL

MARITIME UNIVERSITY

№ 3 (63), 2020

20. Slovar' terminov $i$ opredelenij v logistike [Elektronnyj resurs]. Rezhim dostupa: http://www.baif.by/stati/slovar-terminov-i-opredelenii-v-logistike

21. Aslamova, V.S. Algoritmy resheniya transportnyh, setevyh zadach $i$ zadach o naznachenii [Tekst]: Uchebnoe posobie. Chast' vtoraya / V.S. Aslamova, I.M. Kulakova, M.N. Kolesnik. Angarsk: AGTA, 2008. - 190 s.

22. Ukravtoprom [Elektronnyj resurs]. Rezhim dostupa: http:// ukrautoprom.com.ua/ru/za-rik-bilshe-408-tisyach-vzhivanix-avto popovnili-ukraïnskij-avtopark

23. Den'gi.ua [Elektronnyj resurs]. Rezhim dostupa: http://dengi.ua/ archive/articles/312441-Avto-s-probegom-prodajut-pochti-darom

24. Unian. Informacionnoe agentstvo [Elektronnyj resurs]. Rezhim dostupa:https://www.unian.net/economics/transport/10631775ukraincy-s-nachala-goda-kupili-inomarok-na-1-7-milliarda.html

25. Finance.ua [Elektronnyj resurs]. Rezhim dostupa: https://news. finance.ua/ru/news/-/455524/amerikanskie-b-u-avto-zavoevyvayutrynok-za-chto-ukraintsy-polyubili-avto-iz-ssha

Стаття надійшла до редакиї 10.03.2020

Посилання на статтю: Поддубная Н.Н., Василенко А.О., Ковтун И.А. Оптимизация логистических операций при построении маршрутов доставки // Вісник Одеського національного морського університету: Зб. наук. праць, 2020. № 3 (63). C. 118-142. DOI 10.47049/ 2226-1893-2020-3-1183-142.

Article received 10.03.2020

Reference a JournalArtic: Poddubnaya N., Vasilenko O., Kovtun I. Optimization of logistics operations when building delivery routes.2020 // Herald of the Odessa national maritime university. 3(63), 118-142. DOI 10.47049/22261893-2020-3-118-142. 